\title{
4
}

\section{A CONDIÇÃO DO TRABALHO NO CAPITALISMO DESTRUTIVO NO BRASIL*}

Daniela Neves

\section{INTRODUÇÃO}

Os processos de precarização, terceirização e informalidade do trabalho são essenciais à expansão do capitalismo. A transformação ocorrida no modelo de organização do trabalho, tornando-o mais e mais flexível, tem sua verdadeira face na nova mobilidade dos/as trabalhadores/as expropriados/as do controle do processo produtivo e tornados disponíveis como mera capacidade produtiva. Os direitos do trabalho contemporâneo não devem ser desprezados, pois expressa longa luta pela redução do controle sobre o trabalho e melhoria das condições de vida dessa classe. Mas também não podem ser considerados como expressão de uma duradoura redução de exploração, uma vez que repousa sobre formas de expropriação que, de maneira aparentemente "natural", impõem aos trabalhadores/as sua própria sujeição. $\mathrm{Na}$ atualidade, o aprofundamento da separação realizada entre a propriedade econômica e as possibilidades de intervenção política agrava as condições do trabalho no Brasil, que se diversifica por demais: são trabalhadores formalizados, tornados pessoa jurídica, "trabalho livre de empregadores/as" ou até a chamada "uberização" do trabalho.

No contexto mundial, o aumento da exploração do trabalho tem sido um dos fatores acionados como tentativa de revigorar e estabilizar a acumulação capitalista, marcada pelo desemprego estrutural. De modo geral, a intensificação da exploração da força de trabalho é acompanhada pelo rebaixamento salarial, retirada de direitos trabalhistas, focalização/

${ }^{*}$ DOI - 10.29388/978-65-86678-37-6-0=f.83-104 
privatização de políticas sociais, o aumento da idade para aposentadoria, e o crescimento de impostos regressivos.

A crise do capital na atualidade, além de seus determinantes estruturais conhecidos - taxa de lucro decrescente associada a taxa de exploração crescente, centralidade na acumulação global do capital portador de juros e concentração/centralização de capitais - tem condicionantes conjunturais da maior importância que complexificam a natureza estrutural da crise, são eles: a disputa pela hegemonia capitalista mundial e a tragédia da pandemia do novo coronavírus (SAR-V-02). No Brasil, a crise capitalista mundial se particulariza pela condição de uma economia destruída - a economia brasileira encolheu $-9,7 \%$ no segundo trimestre de 2020, na comparação com o trimestre anterior o pior resultado desde o início da série histórica, iniciada em 1996 (DIESSE, 2020) - a organização social e institucional democrática abalada e ameaçada, e a crise política marcada pelo avanço de projetos autocráticos e protofascistas.

Amplos segmentos da classe trabalhadora só têm possibilidade de realizar trabalhos cada vez mais precários e repletos de informalidade, seja nos países centrais ou na periferia do capitalismo. Trata-se da pactuação política e econômica dos setores da classe dominante para realizar “ajustes" no conjunto dos direitos sociais e produzir um modelo atualizado de organização do trabalho que favorece a acumulação, amplia a exploração e degrada as condições concretas do trabalho. Neste sentido, pergunta-se: Que tipo de trabalho tem sido oferecido e em quais condições? Qual a relação das ações estatais para a reprodução ampliada do capital, considerando as particularidades do capitalismo brasileiro? Qual a contribuição dos fundamentos marxistas para análise das relações de trabalho no capitalismo destrutivo'?

Considera-se como hipótese de análise que as categorias da crítica da economia política: força de trabalho, exploração, composição orgânica do capital e superpopulação relativa são centrais para a compreensão das atuais determinações nas relações de trabalho, e que o modelo capitalista atual de organização do trabalho radicaliza a flexibilização

\footnotetext{
${ }^{1}$ Pode parecer uma obviedade falar em capitalismo destrutivo, mas o termo nos serve de indicação analítica para qualificar o capitalismo contemporâneo onde nós já estamos vivendo uma situ ação de barbárie permanente, e o sistema insiste em funcionar com a mesma lógica destrutiva, mesmo que a humanidade e a natureza não sobrevivam a ele.
} 
como forma, e impõe aos/às trabalhadores/as mais precarização, terceirização e informalidade a partir de amplo desenvolvimento de forças produtivas e das tecnologias. Para isso, desenvolvemos um estudo de caráter teórico que nos permitiu analisar a condição do trabalho no Brasil contemporâneo, marcado pela crise capitalista e a emergência sanitária mundial provocada pelo novo coronavírus (SARS-COV-2).

Isso posto, o texto está assim organizado: uma primeira parte de análise conceitual sobre o trabalho a partir dos fundamentos marxistas da crítica da economia política, em seguida a exposição do modelo flexível de organização do trabalho no Brasil contemporâneo, e por fim, a crítica à precarização, à terceirização e à informalidade como regra para o/a trabalhador/a.

\section{A CONDIÇÃO HISTÓRICA DO TRABALHO NO CAPITALIS- MO}

A questão central para a acumulação capitalista é a exploração do trabalho. E para entender a validade dessa afirmação, indicamos os aspectos da centralidade do valor da força de trabalho para o modo de produção do capital, e como principal meio de produção. Nos termos da análise marxista da economia política, dentre todos os meios de produção é a força de trabalho, por meio do seu dispêndio e objetivação, que cria um valor novo, adicional, aos objetos transformados em mercadoria.

E o que é força de trabalho? O que é trabalho? Segundo essa mesma tradição analítica, a força de trabalho ou capacidade de trabalho é o conjunto das faculdades físicas e mentais de um indivíduo, postas por ele em atividade todas as vezes que são produzidos valores de uso de qualquer espécie. Em outras palavras, a força de trabalho é a capacidade produtiva de homens e mulheres. De modo sintético, o valor da força de trabalho é determinado pela quantidade de trabalho socialmente necessário à produção de artigos de primeira necessidade exigidos para produzir, desenvolver, manter e perpetuar a força de trabalho. Já o trabalho é a utilização da força de trabalho. Ao trabalhar, o indivíduo gasta sua força de trabalho. Na forma aparente, o capitalista, ao contratar um indivíduo por determinado preço e durante certo período, pagaria a este o valor/preço 
do seu trabalho. Porém, na verdade, o que o capitalista paga ao assalariado é o valor/preço de sua força de trabalho, e não todo o trabalho (MARX, 2013).

$\mathrm{Na}$ sociedade capitalista, a força de trabalho transforma-se em mercadoria e, como as demais, tem seu valor definido pelo conjunto das relações de produção. Ou seja, o valor de uso da força de trabalho, para o capitalista, é a propriedade que tem a força de trabalho para produzir a mais-valia, que isso sim interessa ao capitalista. Já o valor, ou seu valor de troca é igual ao valor dos meios de subsistência necessários à produção, conservação e reprodução da própria força de trabalho. O trabalho em si não é mercadoria, não pode ser vendido, porque não existe trabalho antes de dispêndio de força. $O$ trabalho só existe como utilização da força de trabalho, logo não pode ser vendido antes de existir. Outro importante traço da caracterização do trabalho como não mercadoria, é o fato de que se o capitalista não comprasse a força de trabalho, mas o próprio trabalho, e remunerasse o trabalho comprado, não obteria mais-valia, o que tornaria impossível a própria existência do modo de produção capitalista. Por sua vez, o salário é a forma transformada do valor e do preço da força de trabalho. ${ }^{2}$ O Salário pode ser o pagamento da força de trabalho relativo à duração de um determinado tempo trabalhado (jornada), que chamamos salário por tempo, ou o pagamento em função da quantidade produzida, chamado de salário por peça/produto. Essas possibilidades, de como o trabalhador pode ser remunerado pela venda da sua força de trabalho, sempre provocou grande alienação no conjunto das relações de produção. $\mathrm{O} / \mathrm{a}$ produtor/a direto, transformado/a em trabalhador/a livre pelo capitalismo, e que só tem sua força de trabalho, troca essa força

\footnotetext{
${ }^{2}$ As análises de Marx (2013) sobre o processo de produção capitalista, contidas no Livro I do Capital, indicam a equivalência entre valor e preço da força de trabalho em condições "normais" e reguladas pela lei do valor. Todavia, o autor admite que há uma variação, para mais ou menos, do preço em relação ao valor no contexto do mercado de trabalho e não na natureza das relações que determinam o valor e preço da força de trabalho. Essa variação ocorre porque a acumulação expande a parte constante da composição orgânica do capital, e isso provoca uma alteração, mes mo que relativa, da relação entre a parte constante e variável do capital. O resultado desse processo é a produção permanente de uma população trabalhadora relativamente excedente para as necessidades de valorização do capital. Essa população, como produto da acumulação, torna-se combustível para sua ampliação, na medida que constitui um exército de reserva útil e disponível à exploração. Assim, o preço da força de trabalho vai sofrer incidências desse exercício de reserva no terreno do mercado de trabalho.
} 
por uma parte do valor que foi criado no processo de trabalho, o salário, que se expressa no dinheiro. Esse pagamento pode não ser, em diversos casos, chamado de salário, todavia, o processo que resulta na venda da força de trabalho e consequentemente na exploração do trabalho, permanece inalterado (Cf. MARX, 2013; MANDEL, 1978; ROSDOLSKY, 2001; RUBIN, 1980; SOARES, 1985).

É na forma aparente, da relação entre salário e força de trabalho, que reside alguns importantes elementos da expansão da exploração do trabalho na atualidade. Diversas modalidades na qual os/as trabalhadores/as desenvolvem atividades são venda de força de trabalho, mas aparecem, vistos na superficialidade do fenômeno, como venda de serviço/produto. A necessidade de sobrevivência do/a trabalhador/a, associada às condições particulares do processo de intensificação da exploração nos países da periferia do capitalismo, resultam em achatamento substantivo do preço da força de trabalho no Brasil. As médias salariais são aviltantes e não permitem a reprodução adequada dessa força. O preço da força de trabalho é vendido, em inúmeros setores, abaixo do seu valor, o que implica em grande dificuldade do conjunto da classe trabalhadora brasileira adquirir os meios de subsistência necessários à vida básica, ou seja, à reposição diária de energia para realização de um volume normal de trabalho, sua manutenção como força de trabalho. Mas as formas atuais de exploração brasileira implicam não só em dificuldades reais de manutenção dos/as trabalhadores/as, como também se traduzem em crescente eliminação desse contingente populacional excedente, pois o conjunto dos trabalhos/ocupações/empregos ofertados são cada vez, de um lado, a extensão da jornada de trabalho; e de outro, maior grau de intensidade do trabalho.

Todas essas condições, especialmente os baixos salários/rendimentos/pagamentos aos trabalhadores/as, a ação sistemática do Estado brasileiro de desoneração tributária sobre os custos empresariais com o trabalho e a dilapidação das condições de trabalho, caracterizam a particularidade histórica do mundo do trabalho no Brasil atual.

Para ilustrar essa condição precária, a partir de dados sobre a regulação da contratação de trabalho formal no contexto da pandemia do novo coronavírus, podemos indicar, sumariamente, as alterações recentes 
na Consolidação das Leis Trabalhistas (CLT) a partir da Medida Provisória (MP) n ${ }^{\circ} 927 / 2020$, torna Lei Ordinária 14.020/2020. ${ }^{3}$ A Lei 14.020, que dispõem sobre medidas que novamente flexibilizam os direitos do trabalho, sob a justificativa da manutenção do emprego e da renda no enfrentamento da calamidade pública, instituiu o Programa Emergencial de Manutenção do Emprego e da Renda. O Programa permitiu, entre outras alterações na CLT, especialmente a redução de salários e jornadas, e a suspensão de contratos durante a pandemia de Covid-19. Criou um benefício emergencial pago com recursos da União, por até 60 dias ao trabalhador/a com contrato suspenso ou por até 90 dias se o salário e a jornada forem reduzidos. Esses prazos foram estendidos até dezembro de 2020. Ao empregado, é garantida a permanência no emprego pelo dobro do período em que teve o salário reduzido. O salário não podia ter redução inferior ao valor do salário mínimo em vigor em 2020 (R\$ 1.045,00). Esse Programa, apesar de parecer uma ação de manutenção de empregos formais, na verdade autorizou aos empregadores/as reduzir custos com a força de trabalho, e minimizar o impacto da crise para os capitalistas em geral. No momento em que o/a trabalhador/a necessitou da proteção social do Estado para garantir sua vida no meio de uma pandemia viral de grande letalidade, a regulação permitiu que os empregadores/empresários reduzissem salários, logo os rendimentos que permitem a sobrevivência dos indivíduos e suas famílias, sendo essa a realidade dos/as trabalhadores/os formais. O imenso contingente de trabalhadores/as informais ou transformados em pessoa jurídica, ficaram largados à própria sorte, até que o Poder Legislativo aprovou um insignificante ${ }^{4}$ auxílio emergencial, em dinheiro, para trabalhadores/as considerados de baixa renda ou sem renda momentaneamente.

\footnotetext{
${ }^{3}$ Disponível em: <https://www.in.gov.br/en/web/dou/-/lei-n-14.020-de-6-de-julho-de-2020265386938>. Acesso em: 10 out. 2020.

${ }^{4}$ O Auxílio Emergencial foi um benefício instituído no país pela Lei $\mathrm{n}^{\circ} 13.982 / 2020$, que previa o repasse de $R \$ 600,00$ reais mensais, a trabalhadores/as informais e de baixa renda, microempreendedores individuais (MEI), e contribuintes individuais do Instituto do Seguro Social (INSS). O objetivo do auxílio era mitigar os impactos econômicos que foram causados pela pandemia. Inicialmente, estavam previstas três parcelas de $\mathrm{R} \$ 600,00$ reais, mas no início de julho uma $4^{\mathrm{a}} \mathrm{e}$ $5^{a}$ parcelas também foram autorizadas. No dia 01 de setembro, o Governo Federal anunciou o pagamento de mais quatro (04) parcelas de $\mathrm{R} \$ 300,00$ reais até o final de 2020.
} 
A Lei 14.020 que instituiu o Programa, permitiu ainda, a possibilidade de alteração, pelo empregador, do regime de trabalho presencial para o teletrabalho, trabalho remoto ou outro tipo de trabalho à distância. Independentemente da existência de acordos individuais ou coletivos, a decisão será exclusiva do empregador, que deverá notificar o empregado (inclusive o estagiário e o aprendiz) por escrito ou por meio eletrônico no prazo mínimo de 48 horas. Ficando dispensado também o registro prévio da alteração no contrato individual de trabalho, ignorando o disposto no artigo $75-\mathrm{C}, \$ 1^{\circ}$, da CLT. Além disso, o uso de aplicativos e programas de comunicação fora da jornada de trabalho normal do empregado não constituirá tempo à disposição, regime de prontidão ou de sobreaviso, exceto se houver previsão em acordo individual ou coletivo (JESUS; MIRANDA; D’ASSUMPÇÃO, 2020).

No universo do trabalho, onde há a presença de larga desregulamentação, como essas analisadas a pouco, pode-se afirmar que existem modelos de organização do trabalho de ordem mais estruturais, que potencializam a valorização e controle do capital sob o mundo do trabalho? Buscar essa resposta é importante para entendermos a profundidade da reestruturação capitalista permanente. É do que trataremos no item seguinte.

\section{MODELO FLEXÍVEL DE ORGANIZAÇÃO DO TRABALHO NO BRASIL CONTEMPORÂNEO}

A industrialização é marcada pelo aumento das forças produtivas, especialmente pela ampliação da exploração do trabalho. Foi necessário um longo processo e período histórico, dos séculos 18 e 19, para o modo de produção capitalista evoluir da cooperação simples para a grande indústria. Todavia, foi o capitalismo dos monopólios, sob a condição imperialista, o responsável por agilizar o desenvolvimento dos modelos de organização do trabalho ao longo do século 20.

Uma maior organização do trabalho é marcada pelo expressivo desenvolvimento de novas técnicas de produção, aliadas à introdução de novas técnicas de "gerenciamento científico" da força de trabalho. No 
início do século 20 foram desenvolvidas experiências importantes nos EUA, patrocinadas por Frederick Taylor e Henry Ford. Inicialmente, essas novas estratégias de organização do processo de trabalho foram introduzidas nas indústrias de automóveis e tornaram-se, rapidamente, devido aos seus resultados, o padrão produtivo dominante, e generalizaram-se por todas as latitudes no segundo pós-guerra. Esta modalidade de gestão da força de trabalho designa-se, até hoje, como fordista-taylorista.

Nas últimas décadas, as corporações capitalistas vêm desenvolvendo o chamado Toyotismo, modelo flexível de organização do trabalho, que marca a estratégia geral de reestruturação do sistema econômico global, em resposta à sua crise que se manifestou já no final dos anos setenta do século passado e continua até a crise atual. O modelo flexível foi a resposta do capital à recessão econômica mundial de 1973 e seus limites históricos de lucratividade, bem como às crescentes dificuldades em organizar e administrar a força de trabalho: uma necessidade, portanto, dentro de sua lógica, e não uma escolha (ANTUNES, 1998).

Se no fordismo a produção industrial era predominantemente de massa e baseada no uso de ação repetitiva em grandes fábricas, no modelo flexível a produção industrial, e em todos os demais setores, passa por processo ampliado de fragmentação e especialização, graças também ao recurso à novas tecnologias e novos parâmetros organizacionais. A empresa toyotista, em todos os setores da economia privada e da esfera pública, baseia-se na flexibilidade produtiva e organizacional, com o propósito de adaptar sua oferta à demanda do mercado. Desde o sistema de gerenciamento de estoque, baseado no chamado just in time, até a estrutura aparentemente mais democrática de comunicação do kanban, são expressões da flexibilização que impera no atual modelo de organização do trabalho.

Do ponto de vista operacional, o just in time se baseia no método de comunicação incorporado ao kanban que são juntos um comando oculto, já que não é descrito como tal, mas como uma simples modalidade de comunicação de baixo para cima. A ocultação do comando, que na realidade permanece firmemente nas mãos dos principais proprietários e gerentes da empresa, é uma característica peculiar da nova organização empresarial do trabalho. O comando está lá, mas não se pode vê-lo, é 
ainda mais vertical do que antes, em um sistema que se torna, graças à eliminação progressiva de figuras intermediárias, ainda mais rígida e hierárquica do que antes. Mas cria a ilusão de neutralidade, transparência, horizontalidade e autonomia (HARVEY, 1992).

Uma caracterização adequada do modelo flexível de organização do trabalho na atualidade nos leva a destacar, inicialmente, que vivenciamos um período de continuidades e renovações na dinâmica do mundo do trabalho. As continuidades referem-se inegavelmente ao constitutivo traço de intensificação e precarização das formas de comprar e dispor da força de trabalho, todavia, essas formas contêm mudanças que caracterizam as renovadas formas de exploração do trabalho no Brasil, na atualidade.

Flexibilidade renovada se aplica aos processos de trabalho, aos mercados de trabalho, aos produtos, aos serviços e aos padrões de consumo. As renovadas formas de usufruir do trabalho permite atender demandas as mais diversificadas, que se caracterizam pelo "[...] surgimento de setores de produção inteiramente novos, novas maneiras de fornecimento de serviços, novos mercados e, sobretudo, taxas altamente intensificadas de inovação comercial, tecnológica e organizacional" (HARVEY, 1992, p. 140). De acordo com Antunes, esse modelo de dispor da força de trabalho é a tentativa de construção de novos meios de acumulação, e na medida em que é uma forma própria do capitalismo, o ordenamento flexível do trabalho atual mantém três características que lhe são fundamentais: 1. Intensificação da exploração do trabalho; 2. crescimento baseado na exploração do trabalho vivo; 3. o capitalismo, enquanto um sistema de regulação baseado na busca incessante de acumular capital, apresenta uma intrínseca dinâmica tecnológica e organizacional (ANTUNES, 1998).

$\mathrm{Na}$ organização do trabalho atual, o essencial encontra-se na dinâmica, sem precedentes, de incorporação à produção/distribuição/consumo de tecnologias de base microeletrônica associadas às linguagens de inteligência artificial, e na desconcentração produtiva, que provoca uma reorganização territorial, em escala mundial, da produção. A partir do deslocamento, total ou parcial, de complexos produtivos - mediante contratação direta, terceirização, trabalho autônomo domiciliar ou coo- 
perativas de trabalho -, o capital consegue intensificar a exploração da força de trabalho e renova, ainda mais, o caráter desigual e combinado do desenvolvimento capitalista.

A desconcentração produtiva caracteriza-se, ainda, neste mesmo entendimento, pelo deslocamento do emprego e das modalidades de trabalho formal - movimento que ocorre com o fechamento de postos de trabalho na empresa central e abertura de novas frentes de trabalho nos chamados serviços. Essa alteração na gestão e contratação da força de trabalho aponta para alguns autores, entre eles Offe (1995), que o setor de serviços seria supostamente esse novo espaço privilegiado de inserção dos/as trabalhadores/as, visto que, segundo o autor, o setor industrial estaria sendo comprimido a partir da substituição dos/as trabalhadores/ as por máquinas e pela tecnologia. Isto, para Offe, resultaria em mudanças substantivas na centralidade do trabalho nas relações de produção e reprodução social. Ora, diferentemente do que afirma Offe (ibid), entendemos que os/as trabalhadores/as deslocados da empresa central e alocados nas suas concessionárias, subcontratadas e diversas modalidades de serviços - processo esse mediado por renovadas e diversificadas formas de pagamento da força de trabalho (por tempo de trabalho ou por peça/produto) - estariam, medularmente, articulados ao processo de criação de mais-valia e interligados mediante processo de valorização do capital. As empresas e Indivíduos tornados Pessoa Jurídica - IPJ (a chamada pejotização) subcontratados transferem para a "empresa mãe" grande parte do valor produzido em seus processos de trabalho. Mesmo ante a fragmentação e flexibilização, o trabalho seria ainda organizado de modo que a cooperação permanece como eixo vinculador do trabalhador coletivo e mediador dos diversos processos de trabalho. Os IPJ, as pequenas e médias empresas seriam supostamente "prestadoras de serviços" às grandes produtoras, contratadas por tempo determinado ou por produto/serviço, que por sua vez têm em seus quadros trabalhadores temporários, trabalhadores sem emprego regular, que são, principalmente, desprovidos de direitos trabalhistas (NEVES, 2008).

Já que as barreiras das regulações sociais e dos agentes jurídicopolíticos vinham, e vêm, sendo gradativamente derrubadas, o capital monopolista encontra-se cada vez mais livre para operar - para além da ex- 
ploração direta do trabalho - suas estratégias de reificação da vida social e de deslegitimação das lutas e das conquistas sociais. "Realmente, o capitalismo contemporâneo particulariza-se pelo fato de nele, o capital estar destruindo as regulações que lhe foram impostas como resultado das lutas do movimento operário das camadas trabalhadoras" (NETTO; BRAZ, 2006, p. 225). A desmontagem dos sistemas de proteção social nos países centrais, e a destruição dos direitos do trabalho na periferia, a exemplo do Brasil, caracteriza a forma estrutural de organização do trabalho, posto que o capital vem retirando, sistematicamente, os direitos sociais, que são resultados das conquistas históricas da classe trabalhadora. Direitos estes que num mercado de trabalho como o brasileiro, marcado pela precarização e informalidade, são vistos, aparentemente, como privilégios. Ou ainda, nos termos empresariais e do Estado burguês, como custos adicionais desnecessários para a contratação de trabalhadores/as, sobre a qual imporiam uma suposta carga de tributos e despesas excessivas que onera em muito o empresariado e desestimula o desenvolvimento - o que economistas tecnocratas brasileiros denominam de custo Brasil $^{5}$. A redução desses custos tem significado para o/a trabalhador/a brasileiro piores condições de vida e de trabalho, ao passo que não diminuiu o desemprego, nem alavancou o desenvolvimento da economia.

As características aparentes de horizontalidade, autonomia e flexibilidade marcam a estrutura da organização do mercado de trabalho brasileiro, e permitem formas atualizadas de precarização, terceirização e

\footnotetext{
${ }^{5}$ Para boa parte dos economistas, o problema do trabalho no Brasil estaria atrelado ao seu alto custo social, o chamado "custo Brasil". Esta grande vertente dos economistas tecnocratas acredita que a flexibilização do processo de trabalho, do mercado de trabalho e da legislação trabalhista é um elemento fundamental para alavancar o desenvolvimento econômico do país. De acordo com um dos grandes apologistas liberais, "[...] no Brasil, o resultado da soma da Constituição, CLT e jurisprudência da Justiça do Trabalho gera uma enorme inflexibilidade para se negociar condições de trabalho [...] A grande vantagem da contratação coletiva - perdida com a inflexibilidade apontada - é exatamente a das partes acertarem livremente o que mais lhes interessa no momento em que negociam. A competição, o avanço veloz das inovações, a diversidade dos produtos e a globalização da economia estão impondo novas formas de contratação, desconcentração e remuneração da mão-de-obra. Cresce a necessidade do trabalho em tempo parcial; trabalho temporário; trabalho por projeto; teletrabalho etc. Assim como aumenta a necessidade de se fazer arranjos específicos, sob medida, em nível de empresa e de caráter conjuntural" (PASTORE, 1995, p. 183-184).
} 
informalidade. Serão esses os temas que vamos abordar na próxima seção do nosso texto.

\section{PRECARIZAÇÃO, TERCEIRIZAÇÃO E INFORMALIDADE COMO FORMA PREDOMINANTE NO MUNDO DO TRABA- LHO}

Grande contingente da classe trabalhadora brasileira já vivencia historicamente modalidades de precarização, terceirização, subemprego e informalidade no mercado de trabalho. Todavia, é fácil indicar que as formas atuais de precarização ampliam ainda mais esse processo, imprimindo aos trabalhadores/as mais pobreza, exploração e desemprego, uma vez que muitos destes encontram-se totalmente desprovidos de direitos do trabalho.

Diversas pesquisas sobre terceirização e informalidade no Brasil (DRUCK, 2020; ANTUNES, 2020a; CAMPOS, 2018) têm como conclusões unânimes a indissociabilidade desses com a precarização do trabalho em todos os segmentos econômicos nos últimos 25 anos. Os indicadores revelam a degradação do trabalho por meio da violação de direitos trabalhistas, das más condições de trabalho, baixos salários, maiores índices de acidentes e na vulnerabilidade política dos/as trabalhadores/ as.

Em geral, observa-se a existência de momentos distintos de terceirização da força de trabalho no Brasil. A partir de uma temporização feita por Pochmann (2012), podemos indicar que um primeiro momento, observado ainda durante a década de 1980, a terceirização se expressou no movimento de focalização empresarial das atividades especializadas. Em geral, tratou-se da terceirização da força de trabalho correspondente à externalização de partes das atividades que anteriormente eram realizadas internamente, sobretudo nas grandes empresas privadas estrangeiras, com a incorporação de novos métodos de organização da produção e gestão da força de trabalho adotados originalmente nas economias centrais. Nesse momento, houve uma grande expansão da taxa de terceirização ocupacional. "Entre 1985 e 1990, por exemplo, a taxa de terceirização do emprego formal no Estado de São Paulo passou de 
11,7\% para 58,2\% do saldo líquido das ocupações geradas a cada ano" (POCHMANN, 2012, p. 03).

Posteriormente, entre 1990 e 1995, a taxa de terceirização da força de trabalho torna a cair motivada pela crise econômica do início dos anos 1990, e relacionada ainda com a ineficácia dos "planos de estabilização monetária" e a própria abertura comercial que os governos brasileiros foram promovendo no início dessa década. Isso fez com que a chamada modernização das grandes empresas perdesse fôlego nesse momento, e gerou desemprego e alta da inflação. Com o Plano Real e novas regulamentações jurídicas ${ }^{6}$ no campo da terceirização, as contratações de trabalhadores/as formais volta a crescer, o que impulsiona, para cima, um terceiro ciclo de terceirização no país. A partir de dados de Pochmann, "[...] a taxa de terceirização registrou elevação inédita, passado de 8,9\% para 97,6\% do saldo líquido dos empregos gerados no estado de São Paulo entre 1995 e 2002" (POCHMANN, 2012, p. 04). Nesse período, a característica predominante nos indica que a terceirização da força de trabalho, que até então estava relacionada aos interesses das grandes empresas globais, tornou-se uma diretriz para todas as empresas em operação no país. As condições socioeconômicas, especialmente relacionadas à valorização da moeda e regulações de juros e câmbio, permitiu uma maior concorrência entre as empresas que incrementaram em tecnologia aos seus processos, o que produziu uma redução do preço da força de trabalho em diversos setores. Essa redução de custos com o trabalho estimulou o crescimento da terceirização, inclusive o surgimento de empresas sem empregados/as, tudo era terceirizado.

Um quarto momento da terceirização, entre 2000 e 2010, expressa novamente queda nas taxas de contratação da força de trabalho nessa modalidade, onde "[...] a taxa de terceirização passou de 97,6\% para 13,6\% do saldo líquido de empregos formais constituído no estado de

\footnotetext{
${ }^{6} \mathrm{Na}$ falta de regras gerais sobre terceirização no país, valeu por muitos anos a Súmula 331 do Tribunal Superior do Trabalho (TST), editada em 1994, adotada por toda a Justiça do Trabalho. A partir da regulação dessa súmula, serviços terceirizados só poderiam ocorrer em três situações específicas - trabalho temporário, segurança e conservação e limpeza - e em uma hipótese geral — quando os serviços se relacionam à atividade-meio do empregador. Até que, em 2017, duas novas normas liberaram a terceirização geral, inclusive na atividade-fim, no país: a Lei $n^{\circ}$ 13.429/2017 e a Lei 13.467/2017, do governo ilegítimo de Michel Temer.
} 
São Paulo" (POCHMANN, 2012, p. 05). Isso porque as altas taxas de rotatividade nos postos de trabalho, associados a salários inferiores ao $\mathrm{dos} /$ as trabalhadores/as que realizam as mesmas atividades não terceirizados, permitiu uma mudança constante dos/as trabalhadores/as nesses contratos. Outro aspecto importante foi a consolidação da terceirização no setor público, que desloca esses contratos do setor privado e estimula ainda mais o crescimento das tais empresas sem empregados/as, especializadas em prestação de serviços para o setor público. Nos termos de Pochmann, cabe para a nossa análise:

[...] a distinção entre terceirização da mão de obra entre setores privado e público. Este contrata, em geral, serviços de terceirização cujo valor supera em muito o pagamento do servidor ativo, embora o empregado terceirizado receba $1 / 3$, quando muito, na mesma função anteriormente exercida por funcionário não terceirizado. Muitas vezes, a terceirização no setor público termina por responder a regra geral de empregos estáveis ao conjunto dos servidores, especialmente nos postos mais simples da administração (POCHMANN, 2012, p. 05).

Dessa forma, esse novo período de queda da terceirização indica o deslocamento desse tipo de relação de trabalho do setor privado para o setor público, concentrado em algumas áreas de prestação de serviços, especialmente guiados por onde se podia terceirizar e com extrema volatilidade das empresas contratantes de força trabalho terceirizada.

Por fim, indicamos o período atual que marca a terceirização da força de trabalho no país, e pode ser chamado de terceirização indiscriminada e com certa insegurança normativa, pois há generalização das formas de terceirização para diversos setores não tradicionais, e ainda, interpretações no campo jurídico questionam a possibilidade de terceirizar toda e qualquer atividade nos diversos setores. Segundo dados recentes, a terceirização afeta um leque amplo de atividades nesses setores, quais sejam:

Atividades de apoio, manutenção e reparação, Atividades relacionadas à recuperação, Serviços de preparação, Serviços especializados, Representantes comerciais, Atividades auxiliares, Outras ativi- 
dades, Suporte técnico, Outras atividades de prestação de serviços, Fornecimento e gestão de recursos humanos para terceiros, Atividades de monitoramento, Serviços combinados, Atividades de cobrança, Atividades de serviços prestados principalmente às empresas, não especificadas anteriormente, entre outras. (PELATIERI et al, 2018, p. 12).

Associado a essa heterogeneidade, imprecisão e disputa políticajurídica, está a ampliação das taxas de desemprego que marcam os últimos 06 (seis) anos, e forçaram maiores quedas no preço da força de trabalho e engajamento dos/as trabalhadores/as em diversos modelos de trabalho autônomo, tornado pessoa jurídica (PJ, MEI, Cooperativas). Há também forte ação de desregulamentação das leis trabalhistas, dando outras opções às empresas para explorar a força de trabalho, não só por meio de terceirização com contratos formais, mas contratações temporárias/sazonais, em tempo parcial e redução de benefícios. E muitas vezes todas essas possibilidades juntas. Há ainda a informalidade laboral já conhecida no Brasil de longa data. Todavia, a informalidade atual tem elementos novos, os quais passamos a analisar a seguir.

O trabalho informal deve ser entendido como aquela atividade de trabalho que é desenvolvida sem formalização, carteira assinada, ou qualquer tipo de contribuição para o sistema de previdência. Nesse campo, podemos encontrar um conjunto imenso e diversificado de pessoas que têm no trabalho informal sua única fonte de renda. O que mais caracteriza o trabalho informal no Brasil são as atividades com baixa formação, rendimentos insignificantes e instáveis. Esses traços são tão fortes, que alguns pesquisadores/as da área afirmam que muitos desses/as trabalhadores/as informais devem ser considerados desempregados/as, especialmente por não ter um salário básico ou qualquer proteção trabalhista. Indicamos abaixo a distribuição de trabalhadores/as considerando tanto os trabalhos formais quanto informais, no período de 2015 a 2018.

Ao analisarmos essas séries históricas, verificamos que o número de trabalhadores/as informais é imenso e estável na totalidade do mercado de trabalho do país, chegando a percentuais acima de $40 \%$. 
Tabela 01 - Trabalhadores/as considerando tanto os trabalhos formais quanto informais. Brasil (2015 a 2018)

\begin{tabular}{c|c|c|c|c}
\hline $\begin{array}{c}\text { Total de trabalhadores/as (em } \\
\text { mil) }\end{array}$ & 2018 & 2017 & $\mathbf{2 0 1 6}$ & $\mathbf{2 0 1 5}$ \\
\hline $\begin{array}{c}\text { Emprego/a no setor privado com } \\
\text { carteira assinada }\end{array}$ & 32.929 & 33.340 & 34.293 & 35.699 \\
\hline $\begin{array}{c}\text { Empregado/a do setor privado } \\
\text { sem carteira assinada }\end{array}$ & 11.189 & 10.707 & 10.147 & 10.081 \\
\hline $\begin{array}{c}\text { Trabalhador/a doméstico } \\
\text { Trabalhador/a doméstico com } \\
\text { carteira assinada }\end{array}$ & 1.781 & 1.876 & - & - \\
\hline Empregado/a do setor público & 11.533 & 11.283 & 11.214 & 11.418 \\
\hline Empregador/a & 4.423 & 4.243 & 3.915 & 4.022 \\
\hline Conta própria & 23.340 & 22.683 & 22.523 & 22.246 \\
\hline Trabalhador/a familiar auxiliar & 2.190 & 2.214 & 2.122 & 2.600 \\
\hline
\end{tabular}

Fonte: ILAESE (2019), a partir da Pesquisa Nacional por Amostra de Domicílios contínua (IBGE/PNADC).

Dados de fevereiro de 2020, também da PNAD Contínua (IBGE), mostraram um aumento da informalidade, que atingiu 41,6\% da força de trabalho em todo o país, alcançando 38,4 milhões de pessoas, um milhão a mais do que no ano anterior. De acordo com a pesquisa, em 11 estados a informalidade alcança mais de 50\% da população ativa, com destaque para Maranhão e Pará, onde os índices estão acima de 60\%. Outros 15 estados têm taxa de informalidade entre 30\% e 50\%. Pernambuco é o maior nessa faixa, com 48,8\%. Somente duas unidades federativas ficaram abaixo de 30\%: Santa Catarina, com $27,3 \%$, e o Distrito Federal, onde 29,6\% dos trabalhadores sobrevivem sem registro formal. 
A análise de todos esses dados reforça a necessidade de qualificar como os/as trabalhadores/as têm desenvolvido suas atividades laborais informais no contexto atual marcado por crise, recessão econômica e suspensão/reorganização do trabalho em função da pandemia do novo coronavírus, visto que se articulam formas tradicionais de informalidade à novas modalidades de trabalho determinadas pelas necessidades atuais de aumento da lucratividade, com redução de trabalho vivo e expansão do trabalho morto a partir de tecnologias diversas. Para explicar esse cenário, vamos destacar dentre os/as trabalhadores/as por conta própria/ subemprego, aqueles/as que estão vendendo sua força de trabalho mediado por plataformas, aplicativos e serviços nessa era digital.

A necessidade de isolamento físico entre as pessoas, como forma primordial de proteção à saúde coletiva, propiciou a expansão da venda da força de trabalho e serviços por meio de plataformas digitais e de aplicativos integrados à rede mundial de computadores (internet). Um contingente expressivo de pessoas está vinculado às inúmeras empresas que cresceram com a oferta de serviços/produtos/mercadorias mediada por essas plataformas digitais. Ampliou-se, assim, as péssimas condições de oferta de trabalho que podem ser caracterizadas pela informalidade: não há vínculo algum com o tomador do trabalho/serviço; pelos baixos salários: os/as trabalhadores/as dessas plataformas têm rendimentos próximos do salário mínimo, quando não abaixo dele; por jornadas de trabalho extensas: as pessoas trabalham várias horas pois não há horários fixos, e em geral se trabalha em horas nas quais seriam horários vagos e de descanso na jornada de trabalho regulamentada; os comandos e diretrizes do trabalho são externas e superiores ao processo de trabalho que o indivíduo realiza - há uma hiper parcialização dos processos, e cada trabalhador/a tem pouquíssima autonomia para determinar aspectos do trabalho, eles vêm prontos para execução.

A condição geral do conjunto da classe trabalhadora, especialmente o desemprego e a baixa renda, e a escassez de postos de trabalho, obriga a vinculação de trabalhadores/as que estão buscando emprego à essas empresas: Uber, Ifood, Uber Eats, 99, Rappi, Amazon, Mercado Livre, entre outros. Migram do desemprego para a informalidade, mas de 
um modo particular, superexplorados/as, o que Antunes (2020b) chama de nova modalidade de servidão.

Podemos afirmar que essa é uma tendência estruturante dos modos de organização do trabalho no capitalismo contemporâneo, com o desenvolvimento das forças produtivas e outras tecnologias. A tendência, visível bem antes da pandemia, reafirma a crescente redução do trabalho vivo e um novo período de ampliação do que de trabalho morto. Ou seja:

[...] a redução do trabalho através da substituição das atividades tradicionais por ferramentas automatizadas e robotizadas sob o comando informacional-digital, tornando o trabalho vivo mais "residual" nas plantas digitalmente mais avançadas e empurrandoo para as atividades ditas "manuais" ou ampliando o monumental exército sobrante de força de trabalho, que não para de se expandir nesta fase mais destrutiva do capital (ANTUNES, 2020b, s/p).

Embora o trabalho vivo esteja sendo reduzido, é exatamente nesse tempo de necessidade de isolamento físico e suspensão de todas as atividades que a classe trabalhadora tem uma grande lição da centralidade da força de trabalho como criador do valor e da lucratividade do capital. Sem que o conjunto de trabalhadores/as realizem suas atividades não há lucro, não há valorização do capital, não há produção de riqueza, não há o tal do "desenvolvimento econômico", assim denominado pelos economistas tecnocráticos. Segundo o governo brasileiro, os/as trabalhadores/as não podem ficar em casa para cuidar de sua saúde e "cruzar os braços", pois vai "quebrar" a economia. Dessa forma, fica evidente que mesmo o trabalho vivo estando em número reduzido proporcionalmente ao uso trabalho morto, só esse tem a capacidade de produzir mercadorias e riqueza social para o capital, nessa sociedade desigual.

Estamos, portanto, indicando que as tendências destrutivas do capitalismo atual, no contexto da pandemia e antes dela, escancaram a intensificação da exploração do trabalho, e chegam a desenvolver até formas de eliminação da força de trabalho em contextos determinados. A terceirização, a informalidade e o desemprego, que são produtos cons- 
tantes do modelo atual de exploração, têm contornos repaginados, pois o capital desenvolveu formas eficientes de dilapidar e enfraquecer a força de trabalho. O modelo atual flexível de gestão e organização do trabalho, no qual tratamos em item anterior deste capítulo, vem permitindo que as estruturas de gestão do capital, seja seu alto escalão executivo ou o poder estatal, criem e manipulem formas de reduzir direitos, ampliar a extração de valor, reduzir custos da produção, especialmente salários, e eliminar barreiras de proteção social e direitos humanos.

\section{CONCLUSÃO}

Este capítulo produzido no percurso da pesquisa acerca das condições que incidem sobre o trabalho no capitalismo destrutivo, buscou, inspirado em alguns elementos da contribuição marxista, demonstrar a relevância de categorias ontológicas e reflexivas da crítica marxista da Economia Política para analisar o mundo do trabalho e alguns de seus condicionantes atuais.

Explicitar as características que marcam a condição do trabalho, em particular a precarização, terceirização e informalidade, nos permitiu afirmar a condição renovada da dinâmica sociometabólica da desigualdade que marca esse modo de produção e reprodução social. É evidente que estão em curso diversos experimentos mobilizados pela diversidade de tecnologias que vêm aprimorando a produtividade do trabalho: algoritmos, big data, inteligência artificial, internet das coisas, automações diversas da era digital, que buscam se apoderar do máximo de trabalho. Certamente, a destruição completa dos direitos do trabalho e a submissão da força de trabalho ao controle da teia do capital são parte importante do objetivo constante de eliminar todas as barreiras da expansão capitalista, e os processos em curso no mundo, e especialmente no Brasil, têm obtido relativo sucesso, mas não sem resistências da classe trabalhadora ou de causalidades próprias do capitalismo e suas crises. A resistência de trabalhadores/as tem sido abalada duramente pela fragilização que a organização coletiva, especialmente sindical, sofre devido aos processos ampliados de alienação e destruição de identidades de classe. O tempo presente do trabalho promove cada vez mais individuação e isola- 
mento, pobreza e desigualdade que só podem ser alterados pela ação histórica e coletiva da classe trabalhadora, apoiada em boas tentativas de interpretação da realidade que vivemos, com pesquisa crítica que se some ao trabalho coletivo de inúmeros pesquisadores/as que têm compromisso com a vida da população desse país. Esse é o objetivo principal deste texto.

\section{REFERÊNCIAS}

ALVES, G. Terceirização: o futuro do trabalho no Brasil. Trabalho, Educação e Saúde, Rio de Janeiro, v. 15, n. 2, p. 337-345, 2017.

ANTUNES, R. Adeus ao trabalho? ensaio sobre as metamorfoses e a centralidade do mundo do trabalho. 5. ed. São Paulo: Editora Cortez, 1998.

Coronavírus: $\mathbf{O}$ trabalho sob fogo cruzado. E-Book. São Paulo, Boitempo, 2020a. Disponível em: <https://aterraeredonda.com.$\mathrm{br} /$ coronavirus-o-trabalho-sob-fogo-cruzado/>. Acesso em: 10 out. 2020 .

O privilégio da servidão: o novo proletariado dos serviços na era digital. São Paulo: Boitempo, 2020b.

CAMPOS, A. G. (org.) Terceirização do trabalho no Brasil: novas e distintas perspectivas para o debate. Brasília: IPEA, 2018.

\section{DIÁRIO OFICIAL DA UNIÃO. MP. Medida Provisória $\mathbf{N}^{\mathbf{9}}$ 927, DE}

22 DE MARÇO DE 2020. Disponível em: <https://www.in.gov.br/ en/web/dou/-/lei-n-14.020-de-6-de-julho-de-2020-265386938>. Acesso em: 10 out. 2020 .

DIEESE. Que Brasil emergirá da crise do coronavírus? Boletim de Conjuntura, Setembro/outrubro. Disponível em: <https://www.diee- 
se.org.br/boletimdeconjuntura/2020/boletimConjuntura024.html>. Acesso em: 10 out. 2020.

DRUCK, G. Entre os que permaneceram trabalhando em atividades consideradas essenciais na pandemia, uma grande parte é de terceirizados. EPSJV/Fiocruz, 08/10/2020. Disponível em: <https:/ / www.epsjv.fiocruz.br/noticias/entrevista/entre-os-que-permaneceramtrabalhando-em-atividades-consideradas-essenciais-na $>$. Acesso em: 10 out. 2020 .

HARVEY, D. Condição pós-moderna. São Paulo: Loyola, 1992.

ILAESE. Anuário Estatístico do ILAESE: trabalho \& exploração. v. 1, n. 02. São Paulo: ILAESE, 2019.

JESUS, A. B. B.; MIRANDA, R. S. de; D’ASSUMPÇÃO, W. R. A Medida Provisória n. 927 e seus impactos nas relações de trabalho. UERJ Labura. 04/04/2020. Disponível em: <https:/ / uerjlabuta.com/2020/04/04/a-mp-927-2020-e-seus-impactos-nas-relacoes-de-trabalho/>. Acesso em: 29 jun. 2020.

MANDEL, E. Iniciação à teoria econômica marxista. Lisboa: Editora Antídoto, 1978.

MARX, K. O Capital: crítica da economia política. Livro 1: o processo de produção do capital. São Paulo: Boitempo, 2013.

NETTTO, J. P.; BRAZ, M. Economia Política: uma introdução crítica. São Paulo: Cortez, 2006.

NEVES, D. Reestruturação capitalista e trabalho: notas críticas acerca da economia solidária. Revista Katálysis, Florianópolis, v. 11, n. 01, p. 5360, jan/jun. 2008. 
OFFE, C. Capitalismo Desorganizado - transformações contemporâneas do trabalho e da política. São Paulo: Brasiliense, 1995.

PELATIERI, P. et al. Terceirização e precarização das condições de trabalho: condições de trabalho e remuneração em atividades tipicamente terceirizadas e contratantes. In: CAMPOS, A. G. (org.). Terceirização do trabalho no Brasil: novas e distintas perspectivas para o debate. Brasília: Ipea, p. 11-31. 2018.

PASTORE, J. O 'custo Brasil' na área trabalhista: propostas para modernização das relações de trabalho. In: VELLOSO, J. P. dos R. (coord.). O Real e o Futuro da Economia. Rio de Janeiro: José Olympio, 1995.

POCHMANN, M. As Relações de Trabalho Terceirizado. In: SEMINÁRIO 20 ANOS DE TERCEIRIZAÇÃO NO BRASIL, , 2012, Brasília. Anais Eletrônicos... Seminário 20 anos de terceirização no Brasil. Brasília: SINDEEPRES, 2012. Disponível em: <https://www.diap.org.br/ images/stories/terceirizacao_nobrasil.pdf>. Acesso em: 29 jun. 2020.

ROSDOLSKY, R. Gênese e estrutura de o Capital de Karl Marx. Rio de Janeiro: Editora Contraponto, 2001.

RUBIN, I. A teoria marxista do valor. São Paulo: Editora Brasiliense, 1980.

SALVADOR, E. Os falsos mitos da desoneração da folha de pagamento. Tributação \& Cidadania, Brasília, ano 1, n. 2, mar. 2011.

SOARES, A. R. Princípios de Economia Política: uma introdução à leitura de O CAPITAL. São Paulo: Global Universitária, 1985. 